\title{
Novel Catalysts, Room Temperature, and the Importance of Oxygen for the Synthesis of Single-Walled Carbon Nanotubes
}

2005

Vol. 5, No. 7

$1209-1215$

\author{
Mark H. Rummeli, ${ }^{*}, \dagger$ Ewa Borowiak-Palen, ${ }^{\ddagger}$ Thomas Gemming, ${ }^{\dagger}$ Thomas Pichler, ${ }^{\dagger}$ \\ Martin Knupfer, ${ }^{\dagger}$ Martin Kalbác, ${ }^{\dagger, \|}{ }^{\dagger}$ Lothar Dunsch, ${ }^{\dagger}$ Oliver Jost, ${ }^{\S}$ S. Ravi P. Silva, ${ }^{\ddagger}$ \\ Wolfgang Pompe,,$^{\S}$ and Bernd Buchner ${ }^{\dagger}$
}

Leibniz Institute for Solid State and Materials Research Dresden, IFW Dresden, P.O. Box 27016 D-01171 Dresden, Germany, Advanced Technology Institute, University of Surrey, Surrey, GU2 7XH, United Kingdom, Dresden University of Technology, D-01062 Dresden, Germany, and J. Heyrovsky Institute of Physical Chemistry, Academy of Sciences of the Czech Republic, Dolejsrnkova 3, CZ-18223 Prague 8, Czech Republic

Received April 14, 2005; Revised Manuscript Received May 18, 2005

\section{ABSTRACT}

In this letter, we show for the first time the use of metal oxides as catalysts in the synthesis of single-walled carbon nanotubes (SWCNTs) using laser ablation. Further, SWCNTs have been synthesized at low temperature (down to room temperature), where their nucleation cannot be explained via fullerene nucleation. The data point to a nucleation mechanism previously not identified, that places a stable oxidized ring as the root cause for the growth of SWCNTs.

The impact of nanomaterials is already significant and will certainly have a much greater impact in the future. The identification of SWCNTs $^{1}$ can certainly be considered as one of the most significant stimulants for research into nanostructures. This is due to their remarkable electronic and mechanical properties. ${ }^{2}$ In turn, this has led to a strong demand of SWCNTs for research and commercial applications. Yet, one of the grand challenges associated with SWCNTs is to obtain a clear understanding of their growth, which in turn will allow one to synthesize or isolate SWCNTs of a particular electronic form (semiconducting or metallic) and of the required diameter and chirality. Nonetheless, great strides have been made in their production over the past decade, and new and exciting findings continue to arise. A recent and notable example is (ref 3) where a very high yield $(99.98 \%)$ of SWCNTs was reported using water vapor in chemical vapor deposition (CVD), and this work is clearly a major step forward for SWCNT production. It is argued that $\mathrm{O}_{2}$ selectively burns away amorphous carbon. Aside from CVD, arc discharge and laser ablation remain

\footnotetext{
* Corresponding author. E-mail: m.ruemmeli@ifw-dresden.de.

Leibniz Institute for Solid State and Materials Research Dresden.

$\div$ University of Surrey.

$\S$ Dresden University of Technology.

"Academy of Sciences of the Czech Republic.
}

the two major synthesis routes for SWCNT production. The strength of laser ablation is that it produces high yield and high quality SWCNTs. ${ }^{4}$ The available catalysts for laser ablated SWCNT production, until now, have been limited to the requirement of at least one of a select few transition metals $^{5}$ (Co, Ni, Rh, Pt) being present in the reaction. These require a relatively high synthesis temperature. In addition, a recent number of investigations into nanotube nucleation and growth mechanisms point to a dominant role played by fullerenes limiting the lower temperature synthesis limits. An external supply of fullerenes lowers this $\operatorname{limit}^{6}$ to temperatures below $600{ }^{\circ} \mathrm{C}$. So-called low-temperature SWCNTs have also been formed using continuous wave $\mathrm{CO}_{2}$ lasers (e.g., refs 7 and 8) or solar furnaces (e.g., ref 9) since no additional heating is required as is usual in pulsed laser ablation systems. However, in these cases the required heat for SWCNT synthesis and fullerene production is provided by the laser or the sun and so differ from low-temperature SWCNT reactions using a standard pulsed laser ablation system, as we report in this letter. Low-temperature SWCNT synthesis is attractive, as it would allow their synthesis to be compatible with microelectronics (below $400-500{ }^{\circ} \mathrm{C}$ ) or biomolecular electronics $\left(60-100^{\circ} \mathrm{C}\right)$. The select metals available for laser evaporation SWCNT synthesis can be 
Table 1. Various Catalysts Used for the SWCNTs Synthesized ${ }^{a}$

\begin{tabular}{|c|c|c|c|c|}
\hline sample name & catalyst [wt. \%] & temp. $\left({ }^{\circ} \mathrm{C}\right)$ & product content & $\begin{array}{l}\text { SWCNT mean diameter } \\
(\mathrm{nm}) \pm 0.1 \mathrm{~nm}\end{array}$ \\
\hline $\mathrm{A}$ & $\mathrm{Ni} / \mathrm{Co}[0.5 / 0.5]$ & 1200 & SWCNT & 1.2 \\
\hline $\mathrm{B}$ & $\mathrm{In} / \mathrm{In}_{2} \mathrm{O}_{3}(\mathrm{Ni} / \mathrm{Co})[25 / 25(0.5 / 0.5)]$ & 1200 & SWCNT & $1.6[1.2,2.4]$ \\
\hline $\mathrm{C}$ & $\mathrm{Fe}_{2} \mathrm{O}_{3}(\mathrm{Ni} / \mathrm{Co})[15(0.5 / 0.5)]$ & 1200 & SWCNT & {$[1.2,2.3]$} \\
\hline $\mathrm{D}$ & $\mathrm{In} / \mathrm{In}_{2} \mathrm{O}_{3}(\mathrm{Ni} / \mathrm{Co})[5 / 5(0.5 / 0.5)]$ & 600 & SWCNT & 1.8 \\
\hline $\mathrm{E}$ & $\operatorname{In}(\mathrm{Ni} / \mathrm{Co})[5(0.5 / 0.5)]$ & 1200 & MWCNT & N/A \\
\hline $\mathrm{F}$ & $\mathrm{Fe}_{2} \mathrm{O}_{3}[5]$ & 1200 & SWCNT & - \\
\hline $\mathrm{G}$ & $\mathrm{In}_{2} \mathrm{O}_{3}[5]$ & 1200 & SWCNT & - \\
\hline I & $\operatorname{Mg} 0[1]$ & $500,650,750$ & SWCNT, MWCNT & 1.4 \\
\hline $\mathrm{H}$ & $\mathrm{In}_{2} \mathrm{O}_{3}[1]$ & R. T. & SWCNT & 1.8 \\
\hline $\mathrm{J}$ & $\mathrm{PbO}_{2}[1]$ & R. T. & SWCNT, MWCNT & 1.5 \\
\hline $\mathrm{K}$ & In [5] & R. T. & SWCNT, MWCNT & 1.8 \\
\hline
\end{tabular}

\footnotetext{
${ }^{a}$ Sample name, catalyst (square brackets denote catalyst weight content), synthesis temperature, content of the produced samples (along with amorphous carbon and catalysts particles), and the mean diameters (determined from optical absorption measurements). Double mean diameters in square brackets correspond to values from bimodal diameter distributions.
}

combined with each other (e.g., ref 10) or other metal-based compounds (e.g., ref 11) to alter the mean diameter, diameter distribution, and yield. Indeed, our initial studies began by admixing metal oxides with a more standard Co-Ni binary catalyst. The results showed unique processes that, on closer inspection, suggested two growth mechanisms were present. Regardless of the synthesis technique, it has been shown that SWCNT growth proceeds from condensed catalyst nanoparticles. If a single mechanism is responsible for SWCNT nucleation is not clear, and other studies indicate that SWCNT growth can be placed in one of two categories; capped growth and circumference growth (see ref 5 and references therein). Our study clearly suggests a capped growth variation, which may also be relevant to other growth systems. The capped growth variation has not previously been reported and does not require fullerenes for the initial nucleation of SWCNTs. We call the nucleation process "nucleation via etched carbon shells (NECS)". In addition, this mechanism has the potential for the controlled formation of SWCNTs of a select diameter and chirality. We show, for the first time, that metal oxides can be used for SWCNT synthesis, providing a larger operating temperature range for SWCNT production in laser ablation, which has applicability in many other growth techniques/processes too.

The SWCNTs were synthesized using a furnace-based pulsed laser evaporation method. The setup is very similar to that described in refs 5 and 12 , with the only difference being that in this case the outer and inner (to restrict the reaction volume) tubes are made from alumina since the oven can reach temperatures as high as $1600{ }^{\circ} \mathrm{C}$. In the present study, temperatures between $1200{ }^{\circ} \mathrm{C}$ and room temperature were used for the synthesis of the SWCNTs. A Q-switched high power Nd:YAG laser (2.5 GW per pulse, pulse width $=8 \mathrm{~ns}$ ) was used to evaporate catalyst containing graphite targets using very high purity materials. Table 1 lists the targets used. The evaporated products were then swept away by the carrier gas (nitrogen) to a water-cooled copper coldfinger behind the target, which provides a well-defined reaction point. Pressures of 1 bar and a gas flow rate of 0.4 $1 /$ min were used for all experimental conditions discussed in this letter. Optical absorption spectroscopy (OAS) mea- surements were conducted with the product dispersed in acetone in an ultrasonic bath and dropped onto a $\mathrm{KBr}$ singlecrystal, giving a thin homogeneous film. A Bruker IFS $113 \mathrm{~V} / 88$ spectrometer was used to obtain the optical absorption spectrum in the energy range $0.35 \mathrm{eV}$ to $2.35 \mathrm{eV}$, with a spectral resolution of $0.25 \mathrm{meV}$. For transmission electron microscopy, these films were floated off the $\mathrm{KBr}$ crystal, in water, and collected on standard $\mathrm{Cu}$ TEM grids (TEM, FEI Tecnai F30). Raman measurements were performed on a Bruker Fourier transform Raman spectrometer with a resolution of $2 \mathrm{~cm}^{-1}$. In addition, Raman measurements were recorded using a T-64000 spectrometer with a $\mathrm{Kr}^{+}$laser at $1.91 \mathrm{eV}$ (Innova 300 series, Coherent).

Table 1 contains information on the targets used and the resultant products. During studies on $\mathrm{InC}$ nanostructures we found that the inclusion of $\operatorname{In}$ and $\operatorname{In}_{2} \mathrm{O}_{3}$ to the binary $\mathrm{Ni}-\mathrm{Co}$ catalysts in a laser evaporation target yielded different mean diameters and diameter distributions when compared to SWCNTs produced by an ablation target containing only the binary catalyst of $\mathrm{Ni} / \mathrm{Co}$ under the same conditions. OAS studies revealed that samples with $\mathrm{In}$ and $\mathrm{In}_{2} \mathrm{O}_{3}$ added to the binary $\mathrm{Ni} / \mathrm{Co}$ catalyst the SWCNT diameter distribution and mean diameter increased. OAS is now a well-established means to determine the mean diameter and diameter distribution of SWCNTs. ${ }^{5,13}$ The absorption intensity from SWCNTs is dominated by transitions between symmetrical pairs of van Hove singularities (vHS) in the SWCNT density of states (DOS). Usually three absorption peaks are observed. The first two correspond to the first two transitions between vHS from semiconducting SWCNTs, which we identify here as the $S_{11}$ and $S_{22}$ peaks, while the third peak corresponds to the first vHS transition in metallic SWCNT, the $\mathrm{M}_{11}$ peak. OAS studies show that samples with In and $\operatorname{In}_{2} \mathrm{O}_{3}$ added to the binary $\mathrm{Ni} / \mathrm{Co}$ (sample $\mathrm{B}$ ) catalyst has a larger diameter distribution and larger mean diameters when compared to the reference sample with only the binary $\mathrm{Ni} / \mathrm{Co}$ catalyst (sample A). Previous studies ${ }^{13}$ showed that a correction factor should be used due to excitonic effects when determining the mean diameter from the $S_{11}$ peak. According to this study, we use the following equation to determine the mean diameter from the $S_{11}$ peak: 


$$
E_{11}-X=2 \gamma_{\mathrm{o}} a_{\mathrm{o}} / d
$$

where $X(0.07 \mathrm{meV})$ is the correction factor, $a_{0}(1.407 \AA)$ is the $\mathrm{C}-\mathrm{C}$ bond length, and $\gamma_{\mathrm{o}}(3 \mathrm{eV})$ is the overlap integral. This yielded a mean diameter for sample A of 1.2 and 1.6 $\mathrm{nm}$ for sample B. Further studies showed that by increasing the distance between the target and the coldfinger, where the produced soot is collected, even larger diameters are obtained. In addition, now a bimodal $\mathrm{S}_{11}$ peak is observed, corresponding to two diameter distributions and that the higher energy peak remains close to $1.2 \mathrm{~nm}$. This is a hint that two growth mechanisms are in operation. The stationary higher energy (first) peak can be attributed to the standard growth mode from $\mathrm{Ni} / \mathrm{Co}$. The second growth mechanism is discussed later.

The observed bimodal $\mathrm{S}_{11}$ peak could also be found by including $\mathrm{Fe}_{2} \mathrm{O}_{3}$ in the ablation target (sample C) instead of $\mathrm{In} / \mathrm{In}_{2} \mathrm{O}_{3}$. However, with $\mathrm{Fe}_{2} \mathrm{O}_{3}$, the secondary $\mathrm{S}_{11}$ peak occurs at higher energies when compared to equivalent conditions. An example of the split structure of the $S_{11}$ peak is shown in Figure 1. This suggests that SWCNT growth can be obtained from metal oxides and that the secondary growth mechanism may be related to the carbon-metal eutectics of the metal (oxide) used. In addition to OAS, Raman scattering can yield information on the diameter from the total symmetric radial breathing mode (RBM) in the low frequency region. The obtained RBM modes can show the presence of SWCNTs and double-walled carbon nanotubes (DWCNTs). But caution must be observed as only limited laser energies are used. There is a linear relation between RBM frequency and inverse diameter $v_{\mathrm{RBM}}=C_{1} / d+C_{2}$. Where $C_{1}$ describes the RBM frequency of an individual freestanding nanotube and $C_{2}$ takes in to account the interaction with the local environment. In this case we used values of 234 and $13 \mathrm{~cm}^{-1}$ for $C_{1}$ and $C_{2}$, respectively. ${ }^{14}$ However, the use of Raman spectroscopy is more complicated as compared to OAS for the determination of the mean diameter, the diameter distribution, and yield of a sample. ${ }^{13}$ The observed RBM modes for samples A, B, and C correlate well with the OAS spectra, viz. the relative intensities of the RBM modes for larger diameters are relatively stronger for samples including metal oxides $(\mathrm{B}, \mathrm{C})$ when compared to the reference sample (A). In addition, samples B and C show the presence of RBM modes between 260 and 300 $\mathrm{cm}^{-1}$, which could be due to an increase in the narrow diameter SWCNT or in the establishment of DWCNTs. TEM analysis of these samples showed the presence of both large and narrow diameter SWCNTs in agreement with the OAS and Raman studies.

We observed that with reducing temperatures for a given sample (B and C), the mean diameter as determined from the secondary mode of the $S_{11}$ peak (lower energy mode) was reduced. The first mode (higher energy) always remained close to $1.2 \mathrm{~nm}$ and so is attributed to the standard SWCNT growth from Ni/Co. Further reducing the temperature to 600 ${ }^{\circ} \mathrm{C}$, where no SWCNTs are observed (due to the lack of fullerene production) from a pure $\mathrm{Ni} / \mathrm{Co}$ catalyst, we did observe SWCNTs when using a target with $\mathrm{In} / \mathrm{In}_{2} \mathrm{O}_{3}$ added

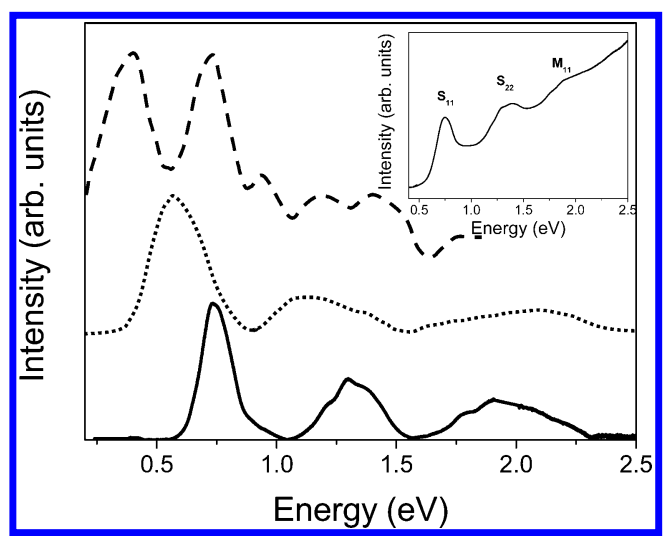

Figure 1. Optical absorption spectra (strapped background) for SWCNTs synthesized with different catalysts and temperatures: solid line - standard $\mathrm{Ni} / \mathrm{Co}$ catalyst $\left(1200{ }^{\circ} \mathrm{C}\right)$, dotted line $-\mathrm{In} /$ $\mathrm{In}_{2} \mathrm{O}_{3}+\mathrm{Ni} / \mathrm{Co}$ catalysts $\left(600^{\circ} \mathrm{C}\right)$, dashed line - (bimodal $\mathrm{S}_{11}$ peak) $\mathrm{Fe}_{2} \mathrm{O}_{3}+\mathrm{Ni} / \mathrm{Co}$ catalysts $\left(120{ }^{\circ} \mathrm{C}\right)$. Inset: Raw optical absorption spectrum of SWCNT using standard Ni/Co catalyst $\left(1200^{\circ} \mathrm{C}\right)$.

(sample D). In this case only a single $S_{11}$ peak is observed. The corresponding OAS spectrum is shown in Figure 1. The $\mathrm{S}_{11}$ position corresponds to a mean diameter of $1.8 \mathrm{~nm}$ and is a far higher diameter than that obtained from pure $\mathrm{Ni} / \mathrm{Co}$ targets, concomitant with the observed RBM modes in Raman spectroscopy. This shows, for the first time, that the addition of a metal oxide to a standard catalyst $(\mathrm{Co}, \mathrm{Ni}, \mathrm{Rh}$, or Pt) can yield SWCNTs at lower temperatures than required without the presence of a metal oxide. It also highlights an additional or altered growth mechanism as suggested by the results at higher temperatures. Furthermore, it strongly suggests a SWCNT growth mode that can be active without fullerenes.

To better understand the growth mechanism for the larger diameter SWCNTs, we examine first the effect of oxygen when synthesizing SWCNT using the reference target (sample A) at $1200{ }^{\circ} \mathrm{C}$. This was done by feeding small quantities of oxygen gas mixed with the carrier gas during ablation (up to 5\%). To our surprise, despite oxygen levels close to that found in air, we still successfully synthesized SWCNTs, and this shows that oxidizing conditions do not automatically suppress SWCNT formation. The corresponding OAS and RBM modes from Raman data showed negligible changes in the mean diameter of the produced SWCNT. This shows that the SWCNT secondary growth mode (when metal oxides are present) is not a function of some oxygen-modified carbon precursors for SWCNT synthesis. Further, an ablation target (sample E) was prepared with only In added to $\mathrm{Ni} / \mathrm{Co}$ and was then ablated at 1200 ${ }^{\circ} \mathrm{C}$ in oxygen-free conditions. The resultant soot showed no SWCNTs when analyzed in OAS or Raman spectroscopy, and TEM studies showed only multiwalled carbon nanotubes (MWCNTs) present. This shows that oxygen alters the carbon precipitation process in metals during the laser ablation reaction. Furthermore, the dilution of the oxide level by adding, for example In to $\operatorname{In}_{2} \mathrm{O}_{3}$, still yielding SWCNTs, shows that only very small quantities of $\mathrm{O}_{2}$ need to be present to prevent MWCNT growth and allow SWCNT growth, and this suggests that the growth is not so much due to a metal 


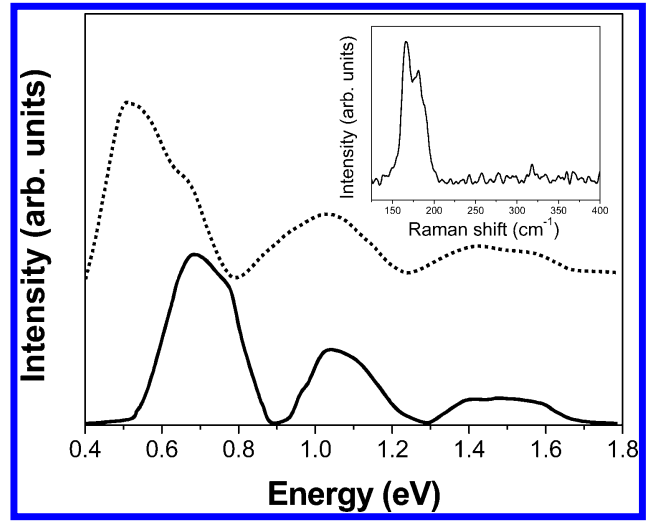

Figure 2. Optical absorption spectra (strapped background) from SWCNT synthesized at $500{ }^{\circ} \mathrm{C}$ using $\mathrm{MgO}$ as the catalyst (solid line) and room temperature using $\mathrm{In}_{2} \mathrm{O}_{3}$ catalyst (dotted line). Inset: Raman spectrum showing RBM mode from SWCNTs synthesized using $\operatorname{In}_{2} \mathrm{O}_{3}$ catalysts at room temperature (exciting laser: $1.91 \mathrm{eV})$.

oxide per se, but more due to the metal with oxygen being present.

A reasonable question then arises as to whether SWCNT growth can occur without $\mathrm{Ni} / \mathrm{Co}$ being included in the target with a metal oxide. We measured various samples produced at $1200{ }^{\circ} \mathrm{C}$ from targets containing only $\mathrm{Fe} / \mathrm{Fe}_{2} \mathrm{O}_{3}$ or $\mathrm{In} / \mathrm{In}_{2} \mathrm{O}_{3}$ (samples F, G respectively) and found no signal corresponding to SWCNTs in the OAS. Raman spectroscopy, which is far more sensitive to the presence of SWCNTs as compared to OAS, showed the presence of a very narrow diameter SWCNTs. Their RBM modes correspond to diameters in the range 0.8 to $1.0 \mathrm{~nm}$. Such narrow SWCNTs can be attributed to nucleation from fullerenes ${ }^{6,15,16}$ or the presence of DWCNTs. The presence of only narrow-diameter SWCNTs would suggest that an alternative mechanism nucleates the larger diameter SWCNTs. TEM studies showed that the catalyst particles from the combined metal oxide and $\mathrm{Ni} / \mathrm{Co}$ ablated samples were far too large (3 to $50 \mathrm{~nm}$ ) to explain the SWCNT growth via circumference growth, as can be found in $\mathrm{CVD},{ }^{17}$ and indicates that the presence of $\mathrm{Ni} / \mathrm{Co}$ plays a role in the large diameter SWCNT formation when including metal oxides at a temperature of $1200^{\circ} \mathrm{C}$. Energy-dispersive $\mathrm{X}$-ray $(\mathrm{EDX})$ analysis shows that the catalyst particles are primarily composed of a single metal with only trace quantities of other metal species, oxygen/impurities. This would suggest that $\mathrm{O}_{2}$ is reduced in the reaction, probably by $\mathrm{C}$. In addition, this suggests that the growth temperature is closer to the carbon-metal eutectic than the carbonmetal-oxide eutectic. Assuming the metal-carbon eutectic is connected to the first stable melt and therefore the upper SWCNT formation limit, ${ }^{12,16}$ we tried using temperatures so low that a first possible melt should (to the best of our knowledge) be present at somewhat higher temperatures. Thus, we attempted synthesizing SWCNTs using only $\mathrm{MgO}$ at $500{ }^{\circ} \mathrm{C}\left(\mathrm{MgO}\right.$ melts at $2830{ }^{\circ} \mathrm{C}$ and $\mathrm{Mg}$ melts at $\left.650{ }^{\circ} \mathrm{C}\right)$. The resultant sample showed the presence of SWCNTs as confirmed by Raman studies, OAS, and TEM (see Figures 2 and 3). The OAS spectrum showed a mean diameter of $1.4 \mathrm{~nm}$. Indeed, using $\mathrm{MgO}$ as a catalyst, we obtained SWCNTs over the three reaction temperatures used (500,

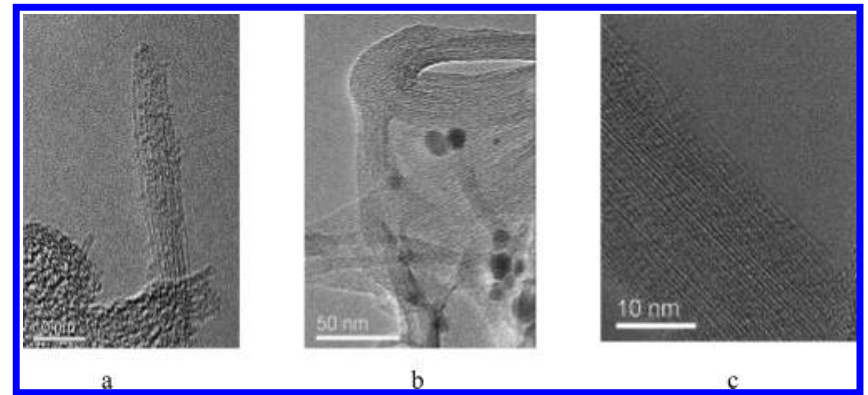

Figure 3. TEM images of SWCNT bundles synthesized with metal oxide catalysts at low temperature: (a) $\mathrm{MgO}$ catalyst at $500{ }^{\circ} \mathrm{C}$, (b) $\mathrm{PbO}_{2}$ catalyst at room temperature, (c) $\mathrm{In}_{2} \mathrm{O}_{3}$ catalyst at room temperature.

650 , and $750{ }^{\circ} \mathrm{C}$ ). As the reaction temperature increased, the mean diameter increased linearly. The diameter distribution did not change with temperature and the diameter distributions are larger than those obtained with a Ni/Co catalyst (cf. sample A). TEM studies showed the presence of SWCNTs, amorphous carbon species, and catalyst particles, along with the presence of some MWCNTs. We also tried synthesizing SWCNTs using only $\mathrm{PbO}_{2}$ and $\mathrm{In}_{2} \mathrm{O}_{3}$ at room temperature $\left(\mathrm{PbO}_{2}\right.$ melts at $290{ }^{\circ} \mathrm{C}$ and decomposes to $\mathrm{Pb}_{3} \mathrm{O}_{4}$, which melts at $830{ }^{\circ} \mathrm{C}, \mathrm{In}_{2} \mathrm{O}_{3}$ melts at $1913{ }^{\circ} \mathrm{C}, \mathrm{Pb}$ and $\mathrm{In}$ melt at $327^{\circ} \mathrm{C}$ and $156{ }^{\circ} \mathrm{C}$, respectively). OAS and Raman studies showed the presence of SWCNTs for both samples (e.g., Figure 2), and TEM studies confirmed the presence of SWCNTs as shown in Figure 3. In the case of $\mathrm{PbO}_{2}$, socalled bamboo-MWCNTs ${ }^{18,19}$ were also observed, while with the $\mathrm{In}_{2} \mathrm{O}_{3}$ sample, no MWCNTs were observed. In addition to the use of the metal oxide catalysts at room temperature we repeated the laser ablation experiment with a target containing only pure indium (sample K). No SWCNT signatures were obtained in OAS studies of the sample. However, Raman studies did show RBM corresponding to SWCNTs and TEM studies confirmed the presence of SWCNTs. The presence of SWCNTs when using pure In as a catalyst at room-temperature we attribute to air trapped in the target. Since the target is not at high temperature, any $\mathrm{O}$ trapped in the target is not reduced and thus $\mathrm{O}$ will be present during the laser ablation reaction. To reduce the $\mathrm{O}$ content in the target we annealed the target at $400{ }^{\circ} \mathrm{C}$ for $30 \mathrm{~min}$ in argon prior to ablation. TEM studies showed that while some SWCNTs were still present (due to remaining $\mathrm{O}$ ), in addition, now MWCNTs were also present supporting the hightemperature results where there is an interplay between the $\mathrm{O}$ content and the formation of different nanotubes

Despite the lower SWCNT yield when using metal-oxide catalysts as compared to standard catalysts, the results do show, for the first time, that metal-oxides can be used as catalysts for laser ablated SWCNT synthesis and at temperatures well below those normally associated with laser ablation SWCNT synthesis. Early optimization studies on the reaction parameters such as catalyst composition, gas pressure/type/flow rate, and temperature show the yields can be significantly improved.

The results suggest that the inclusion of a metal oxide with $\mathrm{Ni} / \mathrm{Co}$ or a metal oxide alone to an ablation target yield 
SWCNTs through an alternative or modified mechanism. Furthermore, from studies with the inclusion of a metal oxide with $\mathrm{Ni} / \mathrm{Co}$, OAS (bimodal) results show that the mean diameter from the "secondary" growth mechanism is dependent on the distance between the target and the coldfinger and also the temperature.

These observations can be explained if one assumes that the metal-based molten catalyst particles are able to nucleate SWCNTs and that the metal(oxide) catalyst (metal with a low melting point) will have a different temperature growth window as for $\mathrm{Ni} / \mathrm{Co}$. Thus, the growth window for the metal(oxide) catalyst will lie in a cooler region of the oven (particularly in the case of In). The results also show that these metal oxide catalysts (with no other catalyst) most likely grow SWCNTs through fullerene nucleation when the reaction temperature is sufficiently high to allow fullerene formation. At these higher temperatures $\left(1200^{\circ} \mathrm{C}\right)$, the inclusion of $\mathrm{Ni} / \mathrm{Co}$ allows larger diameter SWCNTs to be grown and higher SWCNT yields. Thus, in this case, $\mathrm{Ni} / \mathrm{Co}$ also plays a role in their growth, and since these particles will be solidified in the cooler growth window of the added metal (oxide), this points to solidified particles participating in the nucleation or growth of the secondary process in some form.

The circumference growth mechanism, as found in CVD SWCNT growth, ${ }^{5,17}$ is unlikely, and all results point to a capping mechanism. ${ }^{5}$ The actual ablating process from the laser decomposes material from the target in a gaseous cloud such that the metal oxides are cracked and it is not hard to then see that as clusters and nanosized metal particles form after ablation, the concentration of oxygen is reduced so that the molten metal particles can no longer be considered as "oxides". Thus, one can picture the active growth particles as more metallic than oxides, and this is substantiated by the low temperatures used. The dilution of $\mathrm{O}$ by, say, mixing In with $\operatorname{In}_{2} \mathrm{O}_{3}$ already hints that it is not so much the metal oxide that is important, but that $\mathrm{O}$ is present, as indicated by the MWCNT obtained in sample $\mathrm{E}$ where $\mathrm{O}$ is excluded. Thus, one can conclude that in some manner $\mathrm{O}$ prevents MWCNT growth. In CVD the fastest SWCNT growth occurs during the early stages of the reaction, when the catalyst is present as an oxide. ${ }^{20}$ Our studies confirm the importance of oxygen for the growth of SWCNTs (for the first time in laser ablation synthesis).

The formation of SWCNTs at low temperatures (below $600^{\circ} \mathrm{C}$ ) makes it very unlikely that fullerene nucleation plays a key role in the formation of SWCNTs at low temperatures. Thus, some other means must nucleate the SWCNT. The high temperature studies in which metal oxides are included with $\mathrm{Ni} / \mathrm{Co}$ suggest solidified particles are involved alongside molten particles. At lower temperatures with low melting temperature metals, this is perhaps not so easily visualized. However, the laser ablation reaction is highly dynamic in that the ablated materials from each laser pulse form a vapor cloud immediately in front of the target that grows outward in a vortex. ${ }^{4}$ As the cloud grows, clusters and particles form catalysts particles from which SWCNTs stem. These catalysts particles, from which SWCNTs grow, are generally accepted to be in a molten state. However the cloud will have a distribution of temperatures and thus the catalyst particles solidify at different times i.e., solid particles are also present. It has been shown that the melting points of nanoparticles can be significantly lower than that of a bulk material (e.g., $300 \mathrm{~K}$ lower for $\mathrm{Au}^{21}$ and $70 \mathrm{~K}$ for $\mathrm{Sn}^{22}$ ) and carbon-metal eutectic points are generally lower than the melting points of pure metals. In addition, the molten catalyst particles that do solidify do so quickly and can do so at a lower temperature than the normal freezing temperature (recalescence). It is due to these under-cooling effects that the best yields of SWCNTs in laser ablation are obtained for temperatures lower than the carbon-metal eutectic points. Thus, at room temperature (no external heating applied), the ablation cloud will still contain a mix of both molten and solidified catalysts particles for metals with melting points not too far above room temperature. Interactions of material between laser pulses (such as remelting of catalyst particles) are unlikely in these studies as the time gap used $(100 \mathrm{~ms})$ is too large for this to be significant. ${ }^{12}$

We propose a growth mechanism, where the abovedescribed mixture of catalyst particles in two states (liquid and solid) enables SWCNTs to form, and this mechanism is illustrated in Figure 4. We argue that solidified catalyst particles form a graphitic shell ${ }^{23}$ due to precipitating carbon (phase separation). These particles can then collide with other metal particles, which are still in a molten state (fully molten or in which the surface remains in liquid form) and which are supersaturated with $\mathrm{C}$ and contain (in some form) oxygen. Whether the diffusion of $\mathrm{C}$ and $\mathrm{O}_{2}$ occurs throughout the whole molten particle or at the surface ${ }^{24}$ is not clear. Oxygen, which is highly reactive, can then etch away part of the graphitic shell surrounding the solidified particle to a point where a stable oxide ring forms (forming the embryonic stage of the SWCNT) and the solidified particle can merge into the molten metal particle. The formation of a stable oxide ring is not unreasonable and is considered to be the reason why preferential oxidation of SWCNT caps occurs when heated in air (e.g., refs 25 and 26). Mazzoni et al..$^{27}$ showed that preferential opening of caps as opposed to the walls is due to the release of its strain energy. In addition, they showed that an oxidized rim is stable.

Following the formation of a cap with a stable oxidized ring, carbon can substitute the oxygen and thus SWCNT growth takes place. Consequently, the diameter (and chirality) of the subsequent SWCNT is defined by the graphitic shell encapsulating the solid catalyst particle. It is possible that the solidified particle has more than one carbon shell; nonetheless, SWCNTs will dominate (as opposed to DWCNT \& MWCNT) since SWCNT growth can be expected from the first stable oxide ring formed. This means that by controlling the solidification point of the catalyst particles one can also control the diameter. This is seen clearly in the high temperature experiments in which the metal oxide is added to $\mathrm{Ni} / \mathrm{Co}$ where the extension of the distance between the coldfinger and the target essentially increases the time that the $\mathrm{Ni} / \mathrm{Co}$ catalysts particles remain molten and during which time they coalesce, forming larger particles. When they reach a cooler zone they solidify and form a carbon 


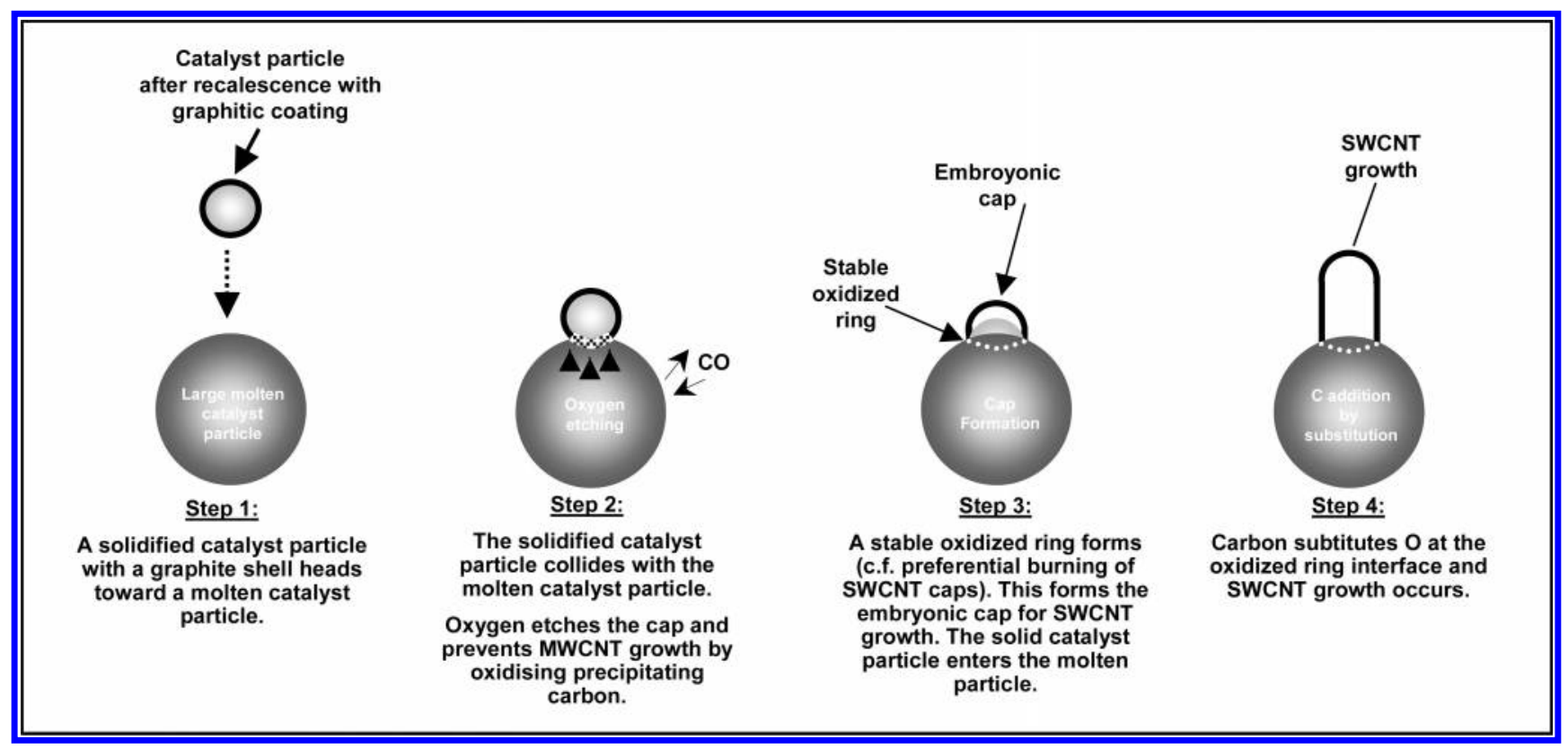

Figure 4. Illustration of nucleation via encapsulated carbon shell (NECS) and subsequent SWCNT growth.

shell before the Fe -or In-based particles solidify. This then explains the appearance of a bimodal diameter distribution and the shift of the secondary diameter distribution with respect to the target to coldfinger distance in the OAS results. It also explains the diameter dependence on temperature as found with the studies using $\mathrm{MgO}$ as a catalyst.

In cases where a bimodal diameter distribution is obtained, the primary diameter distribution does not shift for different target to coldfinger distances. This shows that the coexistence of the metal oxides with $\mathrm{Ni} / \mathrm{Co}$ does not adversely affect the growth of SWCNTs due to Ni/Co (which occurs in a different growth window). This is partially supported by the studies where $\mathrm{O}$ was added to the reaction with a standard $\mathrm{Ni} / \mathrm{Co}$ catalyst and in the unchanged (primary) diameter distribution. This is further supported by the EDX analysis which show the catalysts particles to be dominated by a single metal, and, furthermore, $\mathrm{Ni}$ or Co based catalyst particles are on the whole smaller than those of the added metal (oxide).

The results also show that $\mathrm{O}$ prevents MWCNT formation, and although the exact dynamics are not clear presently, this could be due to the reduction of precipitating $\mathrm{C}$ from a molten particle, i.e., it leaves as CO. CO can also enter molten catalysts particles and act as a source of $\mathrm{C}$.

Such a mechanism can also explain circumference growth in CVD SWCNT synthesis. Often the catalysts particles reside on an oxidized substrate (e.g., refs 28 and 29), which can then provide oxygen for the formation of a stable oxidized ring at the interface of the catalysts particles and the substrate viz., the circumference of the catalyst particle. We aim to conduct studies to verify this. The mechanism can also explain SWCNT synthesis where an alternative (oxide based) support is used (see, e.g., refs 30 and 31).

Further studies are required to verify this mechanism and whether oxygen plays the same roles when using the usual catalysts for laser ablation (Co, Ni, Pt, Rh). Indeed, in laser ablation the diameter of the synthesized SWCNTs is heavily influenced by temperature, gas type, pressure, and flow rate. These parameters will directly influence the size of solidified catalyst particles in NECS. Further, oxygen will always be present in the reaction chamber in small quantities, whether from trapped air in the target or elsewhere. Thus, it may be a universal necessity that oxygen is present to etch carbon shells open and more importantly form a stable oxidized ring from whence SWCNT growth stems.

Finally, such a mechanism would allow the controlled growth of SWCNTs in terms of diameter and chilarity if one used a SWCNT as a template. Dipping one end into an active catalyst would essentially lead to continued SWCNT growth with the diameter and chirality defined by the templating SWCNT.

To summarize, we have shown for the first time that metal oxides can be used as catalysts for SWCNT growth and that by selecting a metal oxide (where the metal has a low melting temperature), SWCNTs can be synthesized even at room temperature without the need for fullerenes. The results make the controlled growth (diameter and chirality) of SWCNT applications in microelectronics and biomolecular electronics more accessible. The presence of oxygen is key to preventing, at least some, metals from precipitating carbon freely and so forming MWCNT. In addition, the role of oxygen is vital to etch open the nucleating carbon shell and in providing a stable oxidized rim, forming an embryonic cap from which subsequent SWCNT growth takes place. The results strongly suggest a growth mechanism previously not identified, which we term nucleation via etched carbon shells (NECS). Future studies should determine how universal such a mechanism is both in terms of different synthesis systems and different catalysts.

Acknowledgment. We thank the DFG PI 440/1. M.H.R. thanks the EU for support through a MC fellowship. The 
authors are grateful to R. Schönfelder, R. Hübel and S. Leger for technical assistance. M.H.R. is grateful to X. Liu and C. Kramberger for fruitful discussions and also to A. Touzik for assistance with the contents figure.

\section{References}

(1) Iijima, S.; Ichihashi, T. Nature 1993, 363, 603-605.

(2) Yakobson, B. I.; Smalley, R. E. Am. Sci. 1997, 85, 324-337.

(3) Hata, K.; Futaba, D. N.; Mizuno, K.; Namai, T.; Yumura, M.; Iijima, S. Science 2004, 306, 1362-1364.

(4) Puretzky, A. A.; Schittenhelm, H.; Fan, X.; Lance, M. J.; Allard, L. F., Jr.; Geohegan, D. B. Phvs. Rev. B 2002, 65, 245425-9.

(5) Jost, O.; Gorbunov, A.; Liu, X.; Pompe, W.; Fink, J. J. Nanosci. Nanotechnol. 2004, 4, 433-440.

(6) Zhang, Y.; Iijima, S. Appl. Phvs. Lett. 1999, 75, 3087-3089.

(7) Maser, W. K.; Munoz, E.; Benito, A. M.; et al. Chem. Phys. Lett. 1998, 292, 587-593.

(8) Maser, W. K.; Benito, A. M.; Munoz, E.; et al. Nanotechnology 2001, $12,147-151$

(9) Laplaze, D.; Bernier, P.; Maser, W. K.; Flamant, G.; Guillard, T.; Loiseau, A. Carbon 1998, 36, 685-688.

(10) Guo, T.; Nikolaev, P.; Thess, A.; Colbert, D. T.; Smalley, R. E. Chem. Phvs. Lett. 1995, 243, 49-54.

(11) Lebedkin, S.; Schweiss, P.; Renker, B.; Malik, S.; Hennrich, F.; Neumaier, M.; Stoermer, C.; Kappes, M. M. Carbon 2002, 40, 417423.

(12) Jost, O.; Gorbunov, A. A.; Möller, J.; Pompe, W.; Liu, X.; Georgi, P.; Dunsch, L.; Golden, M. S.; Fink, J. J. Phvs. Chem. B 2002, 106, $2875-2883$.

(13) Liu, X.; Pichler, T.; Knupfer, M.; Golden, M. S.; Fink, J.; Kataura, H.; Achiba, Y. Phvs. Rev. B 2002, 66, 045411-8.

(14) Kramberger, C.; Pfeiffer, R.; Kuzmany, H.; Zólyomi, V.; Kürti, J. Phvs. Rev. B 2003, 68, 235404-4.
(15) Maruyama, S.; Miyauchi, Y.; Edamura, T.; Igarashi, Y.; Chiashi, S.; Murakami, Y. Chem. Phvs. Lett. 2003, 375, 553-559.

(16) Kataura, H.; Kumazawa, Y.; Maniwa, Y.; Ohtsuka, Y.; Sen, R.; Suzuki, S.; Achiba, Y. Carbon 2000, 38, 1691-1697.

(17) Zhang, Y.; Li, Y.; Kim, W.; Wang, D.; Dai, H. Appl. Phvs. A 2002, $74,325-328$.

(18) Cui, H.; Zhou, O.; Stoner, B. R. J. Appl. Phys. 2000, 88, 60726074.

(19) Endo, M.; Kim, Y. A.; Hayashi, T.; Fukai, Y.; Oshida, K.; Terrones, M.; Yanagisawa, T.; Higaki, S.; Dresselhaus, M. S. Appl. Phvs. Lett. 2002, 80, 1267-1269.

(20) Moisala, A.; Nasibulin, A. G.; Kauppinen, E. I. J. Phvs.: Condens. Matter 2003, 15, 3011-3035.

(21) Gorbunov, A. A.; Jost, O.; Pompe, W.; Graff, A. Carbon 2002, 40, $113-118$.

(22) Borel, B. J.-P. Phys. Rev A 1976, 13, 2287-2298.

(23) Lai, S. L.; Guo, J. Y.; Petrova, V.; Ramanath, G.; Allen, L. H. Phvs. Rev. Lett. 1996, 77, 99-102.

(24) Boskovic, B. O.; Stolojan, V.; Khan, R. U. A.; Haq, S.; Silva, S. R. P.; Nature Materials 2002, 3, 165-168.

(25) Ajayan, P. M.; Iijiima, S. Nature 1992, 358, 220-221.

(26) Ajayan, P. M.; Ebbesen, T. W.; Ichihashi, T.; Iijima, S.; Tanigaki, K.; Hiura, H. Nature 1993, 362, 522-524.

(27) Mazzoni, M. S.; Chacham, H.; Ordejón, P.; Sánchez-Portal, D.; Soler, J. M.; Artacho, E. Phys. Rev. B 1999, 60, 2208-2211.

(28) Li, Y.; Kim, W.; Zhang, Y.; Rolandi, M.; Wang, D.; Dai, H. J. Phvs. Chem. B 2001, 105, 11424-11431.

(29) Kim, W.; Choi, H. C.; Shim, M.; Li, Y.; Wang, D.; Dai, H. Nano Lett. 2002, 2, 703-708

(30) Dai, H.; Rinzler, A. G.; Nikolaev, P.; Thess, A.; Colbert, D. T.; Smalley, R. E. Chem. Phvs. Lett. 1996, 260, 471-475.

(31) Harutyunyan, A. R.; Pradhan, B. K.; Kim, U. J.; Chen, G. G.; Eklund, P. C. Nano Lett. 2002, 2, 525-530.

NL050692V 